\title{
Application of airborne LiDAR and GIS in modeling trail erosion along the Appalachian Trail in New Hampshire, USA
}

\author{
Holly Eagleston ${ }^{\mathrm{a}}$, Jeffrey L. Marion ${ }^{\mathrm{b}, *}$ \\ ${ }^{\text {a }}$ Sandia National Laboratories, P.O. Box 5800, United States \\ ${ }^{\mathrm{b}}$ U.S. Geological Survey, Patuxent Wildlife Research Center, Virginia Tech, 310 W. Campus Dr., Blacksburg, VA 24061, United States
}

\section{A R T I C L E I N F O}

\section{Keywords:}

Trail erosion

Soil loss

Recreation management

Sustainable trail design

Appalachian Trail

LiDAR

\begin{abstract}
A B S T R A C T
Recreational activities can negatively affect protected area landscapes and resources and soil erosion is frequently cited as the most significant long-term impact to recreational trails. This study applied extensive multiple regression modeling of trail soil loss to identify influential factors that managers can manipulate to improve the sustainability of trail design and management. Field measurements assessed soil loss as the mean vertical depth along 135 trail transects across the Appalachian Trail sampled along three $5 \mathrm{~km}$ trail segments in New Hampshire's White Mountains National Forest, chosen due to its exceptionally high use and impact. GIS and LiDAR data were used to create many new variables reflecting terrain characteristics that were expected to influence trail erosion and improve predictive models of trail system soil loss. A variety of terrain and hydrology characteristics were applied to model trail soil loss at three spatial scales: transect, trail corridor, and watershed. The model for each spatial scale and a combined model are presented. The adjusted $\mathrm{R}^{2}$ explaining variation in soil loss is 0.57 using variables from all spatial scales, improving on predictive modeling from earlier studies. Environmental and trail design factors such as slope and watershed flow length were found to be significantly correlated to soil loss and have implications for improved sustainable trail design and management.
\end{abstract}

\section{Introduction}

The Appalachian Trail (A.T.) receives an estimated three million hikers every year and the trail is closed to other types of use (ATC, 2020). The NPS Management Policies direct managers to ensure that any adverse impacts are the minimum necessary, and do not constitute impairment of park resources and values (NPS, 2006). Developing sustainable recreation infrastructure, in this case a long-distance trail that can accommodate high visitation and without adverse resource impacts, is a core management priority. Identifying the factors that substantially influence soil erosion along the trail will help trail managers design, construct, and maintain a more sustainable trail able to resist soil loss, minimize environmental degradation, and enhance visitor experiences.

\subsection{Soil loss on trails}

Resource degradation on trails depends on an array of use-related, environmental, and managerial factors (Marion \& Wimpey, 2017; Rangel, Jorge, Guerra, \& Fullen, 2019; Wimpey \& Marion, 2010). Concentrated traffic pulverizes soil leaf litter and humus layers, which are easily lost through erosional processes. Soils then become exposed and vulnerable to wind or water erosion and compaction (Marion, Leung, Eagleston, \& Burroughs, 2016; Rodway-Dyer \& Walling, 2010). Soil compaction decreases soil pore space and water infiltration, which in turn increases water runoff, soil erosion, and muddiness. Soil loss on trails can also substantially expand the spatial extent of recreational disturbance (Leung \& Marion, 1996), alter natural patterns of water runoff, and cause subsequent turbidity and deposition in streams and other water bodies (Marion et al., 2016). While some degree of visitor impact is unavoidable, excessive impacts threaten natural resources and processes, visitor safety, and the quality of recreational experiences (Leung, Marion, \& Farrell, 2001; Marion, 2016; Peterson, Brownlee, \& Marion, 2018).

Initial trail creation or construction establishes a trail's topographic alignments, trail width, gradient, outslope, and drainage. Numerous trail science studies have documented and described the relationship between different design factors and amount of erosion (Leung \& Marion, 1996; Marion \& Wimpey, 2017; Olive \& Marion, 2009). Previous studies suggest that soil erosion along trails is principally influenced by type and amount of use, trail design and alignment features, soil type, rock content, and the density and efficacy of tread drainage

\footnotetext{
* Corresponding author.

E-mail addresses: hollye1@vt.edu (H. Eagleston), jmarion@vt.edu (J.L. Marion).
} 
features (Marion \& Wimpey, 2017; Olive \& Marion, 2009; Salesa \& Cerda, 2019). Trail grade (slope) and trail slope alignment angle (TSA) are key trail design attributes that influence soil erosion (Leung \& Marion, 1996; Marion \& Wimpey, 2017; Marion, Leung, \& Nepal, 2006; Meadema, Marion, Arredondo, \& Wimpey, 2020). TSA is calculated as the difference between the azimuth of the landform fall-line and the azimuth of the trail as it crosses the fall-line. Both variables relate to how a trail is aligned to the landform topography.

This exploratory research seeks to advance the state-of-knowledge and capabilities offered by trail erosion modeling by applying a comprehensive array of field measurements conducted in June 2015 combined with the exploration of geographic information system (GIS) and airborne light detection and ranging (LiDAR) technologies to create an additional suite of topography, watershed, and trail design variables at multiple spatial scales and extents. Specific objectives include: 1) quantify the severity of soil erosion along sections of the northern A.T.; 2) generate trail and watershed characteristics at multiple spatial scales and extents in GIS using LiDAR-derived digital terrain models; 3) statistically analyze the influence of field and GIS-generated variables in explaining trail soil erosion; and 4) develop a prediction function for soil loss on trails.

\subsection{GIS and LiDAR applications to soil erosion modeling}

LiDAR is an active remote sensing technology used to produce highresolution digital elevation models (DEM). Studies using LiDAR to map soils and geomorphic processes have found that LiDAR metrics in addition to GIS environmental cover data (e.g., soil type, geology, land use, and land cover) enhances prediction models (Greve, Kheir, Greve, \& Bocher, 2012; Jebur, Pradhan, \& Tehrany, 2014, 2015; Sankey, Glenn, Germino, Gironella, \& Thackray, 2010). Topographic metrics from airborne LiDAR have been used in a variety of geomorphic applications, including predicting landslides, erosion potential after a wildfire, gully erosion and forest road-induced erosion (Jebur et al., 2014; Perroy, Bookhagen, Asner, \& Chadwick, 2010; Sankey et al., 2010; Stambaugh \& Guyette, 2008; Tarolli, Calligaro, Cazorzi, \& Fontana, 2013). Some typical variables used in describing geomorphic phenomena relevant to soil erosion on trails include slope, curvature, and topographic roughness and wetness (Rodway-Dyer \& Ellis, 2018; Römkens, Helming, \& Prasad, 2002). Curvature identifies concave versus convex landforms and can segregate based on planform curvature or profile curvature. Planform curvature is perpendicular to the slope and relates to the convergence and divergence of flow across the surface. Profile curvature is parallel to the slope and relates to the acceleration and deceleration of flow across the slope as it indicates the direction of maximum slope. These variables can aid in calculating where along the trail water is collecting or shedding. Topographic roughness is a measure of land surface variability and can be used as a surrogate to estimate the resistance of flows (Smith, 2014). Topographic Wetness Index (TWI) quantifies topographic influence on hydrological processes, specifically how topography alters the location and magnitude of saturated regions of runoff generation (Jebur et al., 2014). Two other metrics employed by hydrologists include watershed head, the difference in elevation from the top of the watershed to the outpour point, and flow length, the distance from the top of the watershed to the outpour point.

\subsection{Using GIS to model trail erosion}

Few studies have examined GIS applications to model trail erosion (Bodoque et al., 2017; Tomczyk, Ewertowski, White, \& Kasprzak, 2017). Previously, digital elevation data ( $10 \mathrm{~m}$ and $30 \mathrm{~m}$ ) have been too coarse to accurately describe erosion processes along trails, which are often only $0.5-1.0 \mathrm{~m}$ in width. Cakir (2005) modeled trail erosion with $3 \mathrm{~m}, 5 \mathrm{~m}, 10 \mathrm{~m}$, and $30 \mathrm{~m}$ elevation data. She found significant relationships between TSA, landform curvature, interaction of grade and
TSA, and trail grade at various resolutions, with $5 \mathrm{~m}$ being the most significant. Tomczyk and Ewertowski (2013) used regression tree analysis to create a predictive model for trail condition from a $5 \mathrm{~m}$ DEM, applying GIS layers to the universal and power soil erosion models and using trail width as their dependent variable. They used similar GISderived indices to the ones presented in this study including curvature, aspect, and landform slope, and found plant communities, elevation, aspect and slope to be important variables. Hawes, Dixon, and Ling (2013) calculated waterflow as the upslope catchment area above the trail segment and predicted trail condition class with 50\% accuracy using GIS-derived trail and landform slope data.

Detection of landscape pattern is sensitive to spatial scale, both spatial resolution and extent of a spatial dataset (Rodway-Dyer \& Ellis, 2018; Turner, O’Neil, Gardner, \& Milne, 1989). Erosion processes are conditioned by soil type, porosity, slope, and substrate rock fragments and these factors can have different relationships to stabilizing sediment at different spatial scales (Poesen, Torri, \& Bunte, 1994). There is an interaction between the hierarchies of spatial scales with small, lowlevel systems being part of a sequence of large, high-level systems (DeBoer, 1992). Cammeraat (2002) describes complex interrelationships of processes with increasing scale while the connectivity of runoffgenerating and runoff-absorbing areas is important at all scales. Variability in soil surface properties and infiltration and the spatial distribution and patchiness of vegetation cover and structure can affect runoff at small scales, while runoff in large watersheds is often a factor of channel width, catchment slope length and morphology and increased storage features (Cantón et al., 2011). When examining sediment yield from watersheds, researchers found watershed area to be an important predictor (Lane, Hernandez, \& Nichols, 1997). Thus, findings are likely to vary by spatial scale so modeling of geomorphic processes must account for spatial scale attributes.

\section{Study area and methods}

\subsection{Study area}

The study area is in the White Mountains National Forest, northeastern U.S. in west central New Hampshire (Fig. 1). The A.T. crosses two ecoregions within the study area: an upland Red Spruce (Picea rubens) and Balsam Fir (Abies balsamea) forest, and a lower elevation Sugar Maple (Acer saccharum), Birch (Betula spp) and Beech (Fagus grandifolia) forest. The terrain varies from steep mountains to gentle valleys with elevations ranging from $440 \mathrm{~m}$ to $1200 \mathrm{~m}$ along the trail. The bedrock is composed of deeply buried and uplifted marine sediments with igneous granite and metamorphic schists, gneisses, and quartzites. Multiple glaciation events have left shallow soils and exposed rock at higher elevations with thin to very deep glacial till deposits over rock. Precipitation varies with elevation, from 400 to $850 \mathrm{~mm}$ per year (PRISM Climate Group, 2004).

\subsection{Sampling}

The Generalized Random Tesselation Stratified (GRTS) sampling method (Stevens \& Olsen, 2004) was employed to select three $5 \mathrm{k}$ segments from the $53 \mathrm{~km}$ of the A.T. within the White Mountains National Forest with LiDAR data. GRTS sampling was also used to select 45 sample points within each segment, with field measurements taken at trail transects located at the 135 sample points. This method provides a spatially balanced random sample of segments and points that minimizes spatial autocorrelation problems, an improvement on earlier fixed interval sampling methods (Leung \& Marion, 1999). The three $5 \mathrm{~km}$ segments provided a diversity of elevations, topography, substrates, and vegetation to support soil erosion modeling at a variety of spatial scales. 


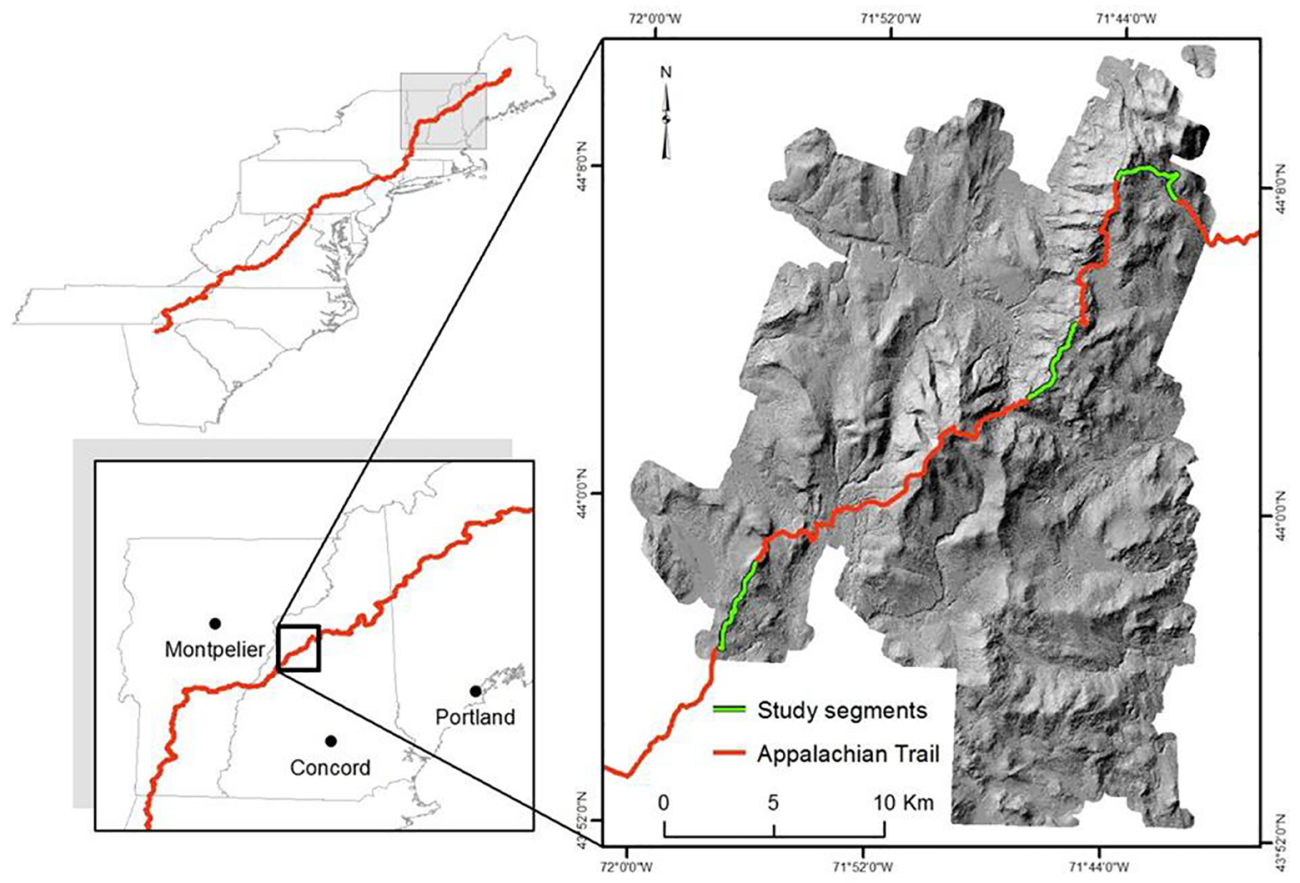

Fig. 1. Study area map of the northeastern U.S. showing states and the study area in west-central New Hampshire (north is up). The inset hill-shade map is the footprint of LiDAR showing a portion of the White Mountains National Forest with the A.T. shown in red and the $5 \mathrm{~km}$ study segments in green. (For interpretation of the references to colour in this figure legend, the reader is referred to the web version of this article.)

\subsection{Field data collection}

In the field, a Trimble XH, 6000 global positioning system (GPS) and global navigation satellite system (GLONASS) receiver was used to locate and record sample points, taking an average of 50 points at each transect location with post-processing corrections of final x,y coordinates. The trail centerline was also recorded with the Trimble by walking the center of each trail segment. Since the averaged transect location points had greater accuracies than the A.T. centerline, the latter was adjusted when necessary to intersect the transect points. For post-processed point data, $48 \%$ of had a horizontal accuracy within $1 \mathrm{~m}$ and $86 \%$ were within $2 \mathrm{~m}$; data points with horizontal accuracy greater than $2 \mathrm{~m}$ were omitted from the study.

Trail soil erosion was measured with the cross-sectional area (CSA) method described by Marion and Wimpey (2017). At each sample point, a CSA profile was established by placing temporary stakes on either side of the trail and stretching a taut line between their bases (Fig. 2). Many studies have focused on measuring tread erosion reflecting current or recent use levels and placed the transect stakes to

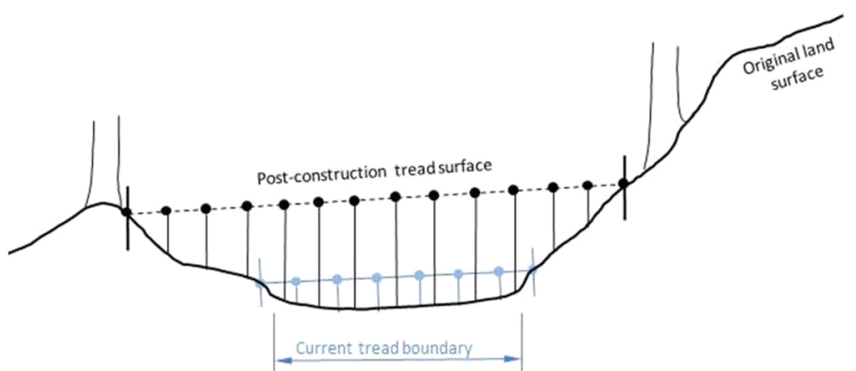

Fig. 2. An illustration of the cross-sectional area method for assessing soil erosion. Both recent and "historic" trail erosion was assessed by configuring the transect stakes and line to reflect post-construction pre-use soil loss. Soil erosion, the dependent variable, was calculated as the mean of vertical measurements taken every $10 \mathrm{~cm}$ along the dashed transect line to the ground surface. Other studies have focused on more recent soil loss reflecting current use levels by assessing soil loss between trail borders that capture approximately $95 \%$ of visually obvious trampling impact, shown by lower transect line within the current tread boundaries. capture an estimated $95 \%$ of foot traffic based on observed disturbance of vegetation and organic litter (Marion et al., 2006; Marion, Wimpey, \& Park, 2011; Olive \& Marion, 2009). In this study the transect stakes and lines were configured to approximate what field staff judged to be the "post-construction" or "pre-use" tread surface based on an examination of smaller scale-topography to capture both recent and older "historic" erosion (Fig. 2). While this is straightforward in flat terrain and for trails aligned with the fall line, judgement based on an understanding of cut-and-fill sidehill trail construction is necessary when positioning stakes for side-hill trails (Figs. 2 and 3). These methods were used because some of the trail soil loss dated from many decades ago and vegetative recovery had occurred along the trail sides, with the current tread centered below. Inclusion of this "historic" trail soil loss with this method provided a greater range of soil loss that was likely to correlate better with terrain characteristics at different spatial scales. Vertical measurements from the transect line to the tread surface were recorded every $10 \mathrm{~cm}$ to the nearest $1 \mathrm{~mm}$. The dependent variable in this study was the mean of CSA vertical measurements from the transect line to the tread surface (Cole, 1983; Leung \& Marion, 1999). This variable, mean trail depth, was chosen because it is not influenced by differences in tread width, which can otherwise inflate or deflate aggregate CSA soil loss values. Other soil loss assessment methods (e.g., drones, total stations) could not be applied due to the remoteness, steep topography, and dense forest cover over the trail segments (Cwiakala et al., 2017; Vinson, Barrett, Aust, \& Bolding, 2017).

The data employed in modeling analyses were collected during field measurements and combined with GIS-derived measures and indices across a variety of spatial scales and extents. At each transect, three spatial scales and associated variables were measured. Previous studies have emphasized characteristics assessed at trail transect locations. This study explored a watershed-driven approach to investigate trail erosion as affected by influential factors at multiple spatial scales. Specifically, we examined three spatial scales (Fig. 4): 1) the transect location, 2) the trail corridor watershed - the trail corridor extending uphill from the sample point to a point where the trail grade reverts downhill (the artificial local watershed), and 3) upslope landform watershed - the larger GIS-delineated watershed that contributes water to the "trail corridor watershed."

At the trail transect, several biophysical measurements were 


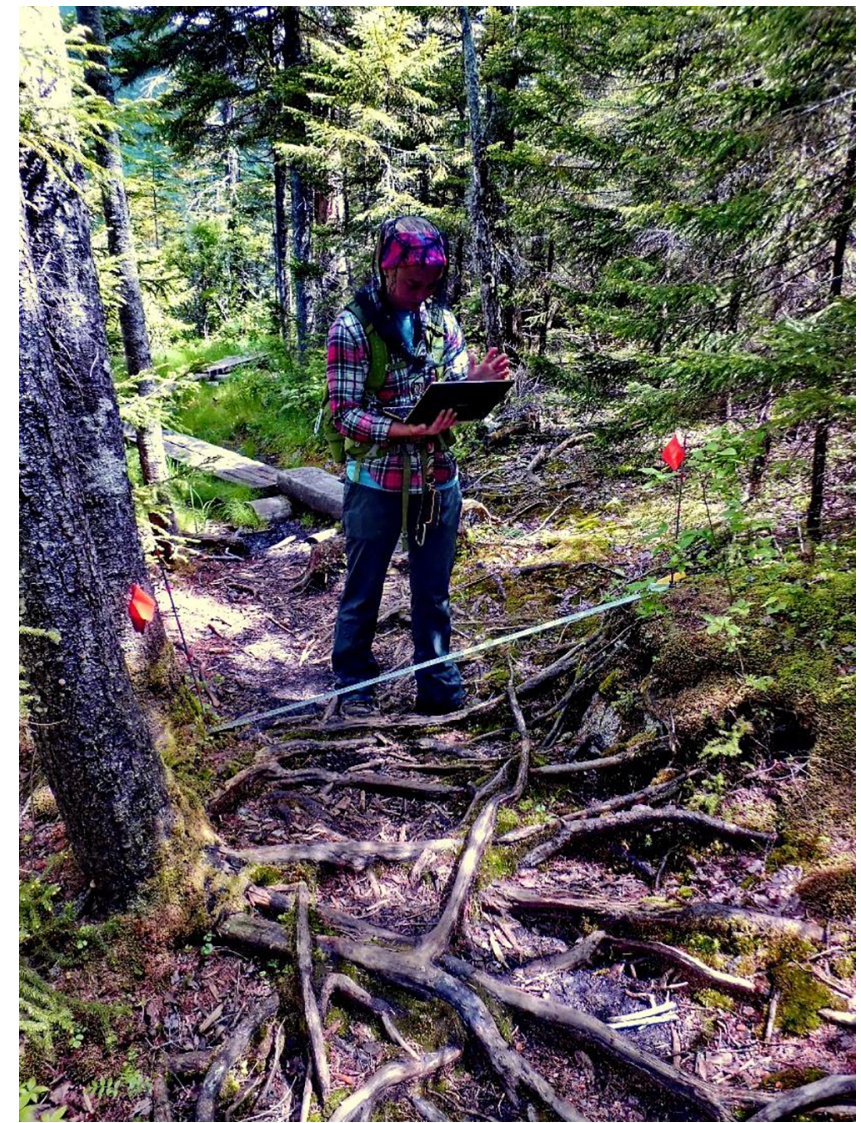

Fig. 3. Field staff measuring an eroded transect with no historic erosion. Due to interfering roots the stake on right side is slightly beyond the trail border.

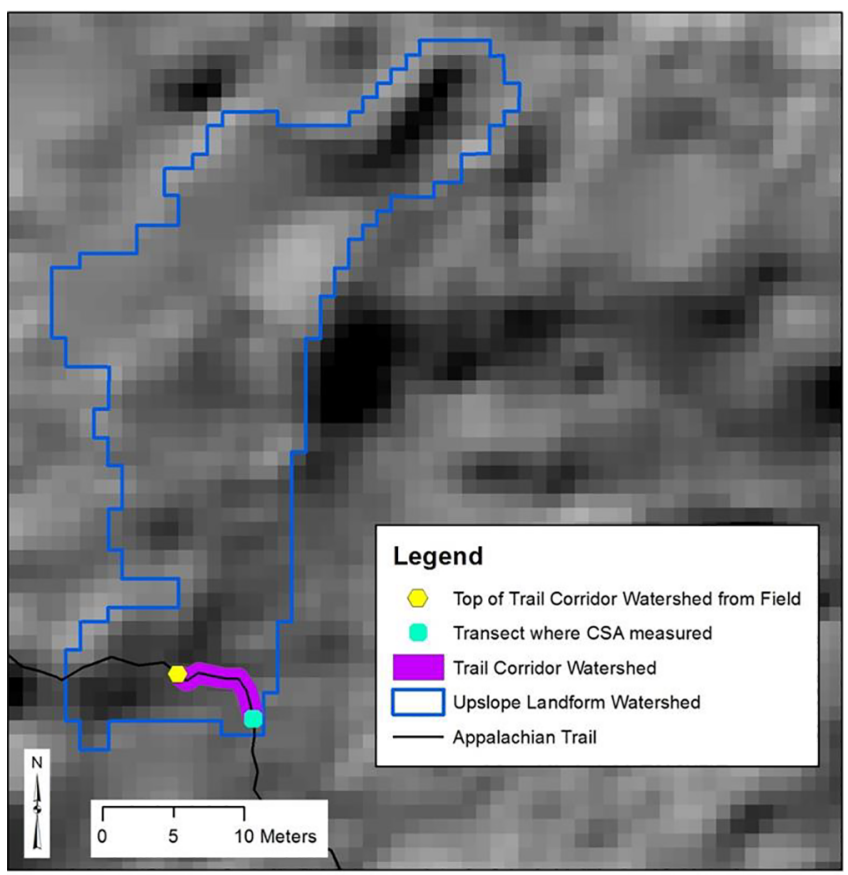

Fig. 4. Three spatial scales of measurement for variables related to trail soil loss. The cyan (lower) point marks the transect location and spatial scale, the purple polygon delineates the trail corridor spatial scale, with the upper boundary marked in yellow (upper point). The larger blue polygon outlined depicts the upslope landform watershed scale, delineating the contributing area to the trail corridor. (For interpretation of the references to colour in this figure legend, the reader is referred to the web version of this article.) recorded as possible independent variables, including soil texture, tread composition, grade, and TSA angle. Tread composition is the relative percentages of vegetation, organic litter cover, exposed soil, exposed roots, rock, gravel and water that occur across the transect line (Marion \& Hockett, 2008; Marion \& Wimpey, 2017; Olive \& Marion, 2009). Trail grade (slope) was measured with a clinometer from the transect to a point on the trail $3 \mathrm{~m}$ distant in an uphill direction. TSA is the smallest difference between the bearing of the trail and the bearing (aspect) of the landform. We note that use data is unavailable within the study area and could not be accurately assessed in our study. However, the three study segments are all within the heavily visited White Mountains and have comparable levels of use.

The trail corridor watershed was defined as the artificial catchment area from the transect uphill along the trail to a point where water is diverted into two directions via a grade reversal or a $100 \%$ effective tread drainage feature such as a water bar (Fig. 4). Its width was the maximum width of the trail for that section. Within each trail corridor watershed, the following attributes were assessed and averaged for each variable: trail slope, TSA, tread width, ground cover, substrate type, and tree canopy cover. Ground cover categories assessed for the trail corridor watershed included vegetation and organic litter, organic and mineral soil, rock $<5 \mathrm{~cm}$, rock $6-30 \mathrm{~cm}$, rock $>30 \mathrm{~cm}$, bedrock, exposed roots, and human-placed wood. Similar tread substrate types were assessed by examining the exposed backslope cut of the trail and tread surfaces.

The upslope landform watershed was defined as the traditional GISdelineated watershed created from the terrain in an uphill direction from the trail transect, including all surface area that could contribute water to the trail transect location. Within this area field assessments were made and averaged for each variable, including groundcover and substrate types, shrub cover, and canopy cover. All measurements taken in the field were recorded on an iPad using Qualtrics $(\mathcal{C}$ offline forms.

\subsection{GIS analyses}

Unprocessed point cloud LiDAR data were available through the U.S. Geological Society (USGS) for a 484 square $\mathrm{km}$ swath of the White Mountains in New Hampshire. This LiDAR was flown at $1 \mathrm{~m}$ nominal point spacing with vertical accuracy of $13 \mathrm{~cm}$ root mean square error by Photo Science, a USGS contractor, during leaf-off season with no snow in November 2011. Given the substantial age of the study trails and preponderance of rock substrates we expect small and inconsequential levels of soil loss between the 2011 LiDAR data collection and field measurements in June 2015. Point cloud data were used to create a $1 \mathrm{~m}$ bare earth DEM model using Optech, GeoCue, Terra Scan and Terra Modeler software for automated classification and manual inspection. The LiDAR footprint covers $53 \mathrm{~km}$ of the A.T. near Lincoln, New Hampshire, $15 \mathrm{~km}$ of which were used in this study (Fig. 1).

Due to their strong influence on trail soil erosion, trail grade and TSA were also computed in ArcMap 10.3 GIS software using the $1 \mathrm{~m}$ Bare Earth DEM derived from the LiDAR data for the three spatial scales. Analytical calculations for surrogate measures of field-collected variables mimicked the field protocols when possible. For GIS-derived variables at the transect spatial scale, raster values were extracted from the cells containing the transect point locations. To calculate TSA for the trail corridor watershed, the trail was segmented into $5 \mathrm{~m}$ sections for TSA calculations and averaged, and by calculating a single TSA value from the start of the trail corridor to the end.

Additional variables derived using GIS techniques included slope, aspect, curvature, flow accumulation, topographic wetness index, topographic roughness, and watershed length and head. Slope, aspect, curvature and flow accumulation were measured using the Spatial Analyst extension in ArcMap 10.3. Slope was measured with the slope tool in ArcMap (calculated for each pixel by looking at a $3 \times 3$ window and determining the change in elevation from left to right and from top to bottom around the center pixel (Horn, 1981), and by using the 
ArcMap output drop raster in the Flow Direction tool (calculated by taking the maximum slope from a center pixel to each of its 8 neighbors in a $3 \times 3$ window (Travis, Elsner, Iverson, \& Johnson, 1975). The ArcGIS Curvature tool calculates the second derivative of a surface within the $3 \times 3$ moving cell window; profile and planform curvature were calculated.

Topographic wetness index (TWI) is calculated by the equation below, where $A_{s}$ is the specific catchment area $\left(\mathrm{m}^{2} \mathrm{~m}^{-1}\right)$ and $\beta$ (radian) is the slope gradient in degrees.

$T W I=\ln \left(A_{s} / \tan \beta\right)$

Topographic roughness was calculated using the ArcMap Focal Statistics tool and varying window sizes $(3 \times 3,5 \times 5 \& 7 \times 7)$ to calculate the standard deviation of elevation within a cell window. The larger the window, the more generalized the product. All kernel sizes were input to the model to evaluate their influence on varying spatial scale.

For the trail corridor watershed spatial scale, the zonal statistics tools (mean and mode) were used to extract raster data. Trail slope at this spatial scale was calculated by: 1) taking the rise/run from the elevations of the transect and the upper trail corridor boundary, and 2) segmenting the trail corridor into $5 \mathrm{~m}$ sections and computing an average.

The upslope landform watershed was delineated using the Watershed tool in ArcMap with the associated trail corridor as the "pour point" (Fig. 4, blue \& purple polygons). The upslope landform watershed GIS variables were calculated using zonal statistics (mean and mode) of slope, topographic roughness, TWI and aspect rasters. Watershed metrics such as flow length and head were also calculated. Precipitation estimates were obtained through application of the parameter-elevation regressions on independent slopes model (PRISM) algorithms that use data from nearby weather stations integrated with DEM data, aspect, and other attributes to interpolate precipitation data for each pixel (PRISM Climate Group, 2004).

Table 1 shows all the variables used for each spatial scale with superscripts denoting variables measured in the field, GIS-derived surrogate measures for field variables, and GIS-derived new variables.

\subsection{Modeling}

Soil loss measured at transects is predominantly from water-born soil erosion, but some loss may be from wind erosion, soil displacement by traffic, and soil compaction (Marion \& Wimpey, 2017). Regression modeling to predict mean tread depth, the dependent variable, employed the independent (predictor) variables (Table 1) measured in the field and derived from GIS analyses. Regression modeling proceeded in two phases. Phase 1 modeling sought to determine the best variable measures from field collected data, GIS-calculated surrogate measures, alternative calculation methods and statistical measures, and spatial scales, as described in Section 2.4. For example, slope was measured in the field and calculated using GIS procedures with two algorithms at three spatial scales. Forward and backward stepwise regression on variables of the same category were modeled with the dependent variable and the Akaike information criterion (AIC) was applied for model selection. This method estimates the quality of the model in relation to other models. The most significant variable was selected from each category and these variables were input into the phase 2 modeling to develop the best predictive model.

For phase 2 modeling a randomized portion (70\%) of the data was used to develop four final predictive models relating to the three spatial scales (Fig. 4) and an integrated model combining variables from all spatial scales. Ordinary Least Squares multiple linear regression was used, and variables were selected through forward and backward stepwise techniques using R software. Five outliers were removed using Cook's Distance threshold and the variance inflation factor and a correlations matrix were examined for each variable to detect

Table 1

List of variables used to predict soil loss at trail transect. Variable categories in bold were reduced to one significant variable for each spatial scale prior to modeling analyses.

\begin{tabular}{|c|c|c|c|}
\hline Variables & $\begin{array}{l}\text { Spatial Scale } \\
\text { Transect }\end{array}$ & Trail Corridor Watershed & Upslope Landform Watershed \\
\hline Slope & $\begin{array}{l}\text { Grade (slope)* Slope ratio (trail slope/ } \\
\text { landform slope)* Slope (Horn \& Travis) } \dagger \\
\text { Slope ratio (Horn \& Travis) } \dagger\end{array}$ & $\begin{array}{l}\text { Mean Grade * Trail watershed grade (entire corridor) } \dagger \text { Trail } \\
\text { watershed grade (mean, } 5 \text { m segments) } \dagger \text { Trail watershed grade } \\
\text { (mode, } 5 \text { m segments) } \dagger \text { Slope ratio (mean trail watershed slope/ } \\
\text { landform slope (Horn \& Travis) } \dagger \text { Slope ratio (mean trail } \\
\text { watershed slope segmented/landform slope (Horn \& Travis) } \dagger \\
\text { Slope ratio (mode trail watershed slope segmented/landform } \\
\text { slope (Horn \& Travis) } \dagger\end{array}$ & $\begin{array}{l}\text { Grade* Mean \& mode Slope (Horn } \\
\& \text { Travis) } \dagger\end{array}$ \\
\hline Trail Slope Alignment & TSA $^{*}$ & Mean TSA * & \\
\hline Angle (TSA) & TSA (trail bearing-landform aspect) $\dagger$ & $\begin{array}{l}\text { TSA (entire corridor) } \dagger \\
\text { TSA (mean, } 5 \text { m segments) } \dagger \\
\text { TSA (mode, } 5 \text { m segments) } \dagger\end{array}$ & \\
\hline Size & & $\begin{array}{l}\text { Length trail watershed* } \\
\text { Trail watershed size }\left(\mathrm{m}^{2}\right) \dagger\end{array}$ & Length* \\
\hline $\begin{array}{l}\text { Precipitation } \\
\text { Soil Texture }\end{array}$ & $\begin{array}{l}\text { Precipitation (PRISM) } \dagger \\
\text { Soil Texture * }\end{array}$ & Precipitation (PRISM) $\dagger$ & Precipitation (PRISM) $\dagger$ \\
\hline Ground Cover & Trail Tread Characteristics* & Mean Ground Cover* & Mean Ground Cover* \\
\hline Substrate Type & & Mean Substrate Type* & Mean Substrate Type* \\
\hline Curvature & $\begin{array}{l}\text { Profile \& Planform Curvatures at } 1,10 \& \\
30 \mathrm{~m} \neq\end{array}$ & Mean \& mode Profile \& Planform Curvatures at $1,10 \& 30 \mathrm{~m} \leftarrow$ & $\begin{array}{l}\text { Mean \& mode Profile \& Planform } \\
\text { Curvatures at } 1,10 \& 30 \mathrm{~m} \neq\end{array}$ \\
\hline Aspect & Landform Aspect * & Mean \& Mode Aspect $†$ & Mean \& mode Aspect $†$ \\
\hline Topographic Roughness & $\begin{array}{l}\text { St. dev. of elevation for } 3 \times 3,5 \times 5 \& 7 \times 7 \\
\text { window } \%\end{array}$ & $\begin{array}{l}\text { Mean \& mode st. dev. of elevation for } 3 \times 3,5 \times 5 \& 7 \times 7 \\
\text { window } \%\end{array}$ & $\begin{array}{l}\text { Mean \& mode st. dev. of elevation } \\
\text { for } 3 \times 3,5 \times 5 \& 7 \times 7 \text { window } \$\end{array}$ \\
\hline Watershed metrics & $\begin{array}{l}\text { Flow Accumulation } \leftarrow \\
\text { Topographic Wetness } \\
\text { Index } \%\end{array}$ & $\begin{array}{l}\text { Sum Flow Accumulation } \leftarrow \\
\text { Mean \& mode Topographic Wetness Index } \%\end{array}$ & $\begin{array}{l}\text { Sum Flow Accumulation } \% \\
\text { Watershed head } \\
\text { Watershed flow length } \\
\text { Mean \& mode Topographic } \\
\text { Wetness Index } \nleftarrow\end{array}$ \\
\hline
\end{tabular}

\footnotetext{
* Field-collected variables.

$\uparrow$ GIS-derived surrogate for field variables.

$\$$ GIS-derived new variables.
} 
Table 2

Regression results of modeling trail soil loss (mean trail depth) at three spatial scales. Sample size of each model is 79.

\begin{tabular}{|c|c|c|c|c|}
\hline \multirow[t]{2}{*}{ Independent Variables } & \multicolumn{4}{|c|}{ Regression Models/Scale } \\
\hline & Transect & Trail Corridor & Upslope Landform Watershed & Combined Spatial \\
\hline Precipitation & $2.6^{\mathrm{a}}(<0.001)^{\mathrm{b}}$ & $2.9(<0.001)$ & $3.4(<0.001)$ & $2.8(<0.001)$ \\
\hline Trail grade at Transect (field) & $2.0(0.044)$ & & & \\
\hline Landform Slope at Transect (Travis) & $0.8(0.129)$ & & & $1.6(0.004)$ \\
\hline TWI at Transect point & $1.1(0.137)$ & & & \\
\hline Trail Corridor Mean Grade (field) & & $3.9(<0.001)$ & & $3.6(0.003)$ \\
\hline Trail Corridor Slope ratio (split/GIS Landform Slope (Horn)) & & & & $17.9(0.146)$ \\
\hline Trail Corridor Mean Substrate Type: Percent Soil & & $-0.3(0.13)$ & & $-0.4(0.048)$ \\
\hline Mean Landform Slope along Trail Corridor (Horn) & & $-1.2(0.015)$ & & $-1.2(0.018)$ \\
\hline Upslope Watershed Head & & & $0.9(0.079)$ & \\
\hline Upslope Watershed Flow Length & & & & $0.3(0.005)$ \\
\hline Mean Landform Slope for Upslope Watershed (Travis) & & & $-0.53(0.091)$ & $-0.8(0.001)$ \\
\hline Constant & -73.5 & -43.9 & -50.1 & -34.6 \\
\hline Adjusted $\mathrm{R}^{2}$ & 0.43 & 0.48 & 0.39 & 0.57 \\
\hline F-stat & 16.51 & 20.02 & 18.88 & 14.96 \\
\hline Residual Standard error & 64.13 & 61.25 & 66.08 & 55.36 \\
\hline
\end{tabular}

${ }^{\text {a }}$ Coefficients of mean vertical depth of soil loss $(\mathrm{cm})$.

b Two-tailed $t$-test significance.

unacceptable levels of multicollinearity. The model was then validated with the $30 \%$ of the field data withheld from the training set using simple linear regression. The validation dataset had a balanced distribution of data points from each of the three A.T. segments.

\section{Results}

\subsection{Regression results}

Results from the regression modeling analyses are shown in Table 2 where the adjusted coefficients of multiple determination $\left(R^{2}\right)$ represent the proportion of explained variation in mean trail depth. The combined spatial scale model performed the best $\left(R^{2}=57 \%\right)$, and its inclusion of variables from each of the spatial scales indicates that the interaction of topography, substrate, and trail design attributes from the transect to the watershed scale all aid in explaining trail soil loss (Table 2). The upslope landform watershed model explained the least variation in soil loss, at $39 \%$. An additional $4 \%$ of the variance was explained with the transect scale model, with another $5 \%$ of variance explained by the trail corridor model (Table 2).

\subsection{Analysis of spatial scales}

The analysis of trail soil loss was analyzed at different spatial scales to identify mechanisms that influence where water is traveling downhill across the landform and along the trail. At the transect scale, precipitation, trail grade and TWI were included in the model, with precipitation $(\mathrm{p}<.001)$ and trail grade $(\mathrm{p}=.044)$ as significant predictors (Table 2). At the trail corridor scale, precipitation $(\mathrm{p}<.001)$ remained in the model, with three new predictors: trail corridor mean grade $(\mathrm{p}<.001)$, trail corridor mean substrate type (\% soil) ( $\mathrm{p}=.130$ ), and mean landform slope along the trail corridor $(\mathrm{p}=.015)$. At the upslope landform watershed scale, precipitation remained in the model $(\mathrm{p}<.001)$, with two new predictors: upslope watershed head $(\mathrm{p}=.079)$ and mean landform slope for upslope watershed $(\mathrm{p}=.091)$

All but two of these variables were included in the combined spatial scale model (Table 2), with seven significant predictors, including: precipitation $(\mathrm{p}<.001)$, mean landform slope for upslope watershed $(\mathrm{p}=.001)$, trail corridor mean grade $(\mathrm{p}=.003)$, landform slope at transect $(\mathrm{p}=.004)$, upslope watershed flow length $(\mathrm{p}=.005)$, mean landform slope along trail corridor $(\mathrm{p}=.018)$, and trail corridor mean substrate type (\% soil) ( $\mathrm{p}=.048)$.

These modeling analyses point to the strong influence of precipitation, which was highly significant in all models. Trail corridor mean grade was also highly significant in the trail corridor and combined spatial scale models (Table 2), and mean landform slope along the trail corridor was also significant in both these modes. Soil loss increases as the grade of the trail corridor increases but for side-hill trails soil loss diminishes as landform grades increase.

In the variable importance plot for the combined spatial scales model (Fig. 5), precipitation accounted for $42 \%$ of the variation in $R^{2}$. Precipitation determines how much water falls onto the trail and surrounding areas that may generate runoff onto the trail, so the more precipitation received, the more soil loss occurs as is expected. The next most influential variables included trail corridor mean grade (15\%), trail corridor substrate $(12 \%)$, and landform slope at the transect (10\%). Slope has different effects on soil loss at different spatial scales and was a significant factor when measured at each spatial scale in the combined model (e.g., landform slope at transect $(\mathrm{p}=.004)$, trail corridor mean grade $(\mathrm{p}=.003)$, mean landform slope along trail corridor $(\mathrm{p}=.018)$, and mean landform slope for upslope watershed $(\mathrm{p}=.001)$ (Table 2).

\subsection{Model validation}

A spatially balanced sample of $30 \%$ of the transects from the three

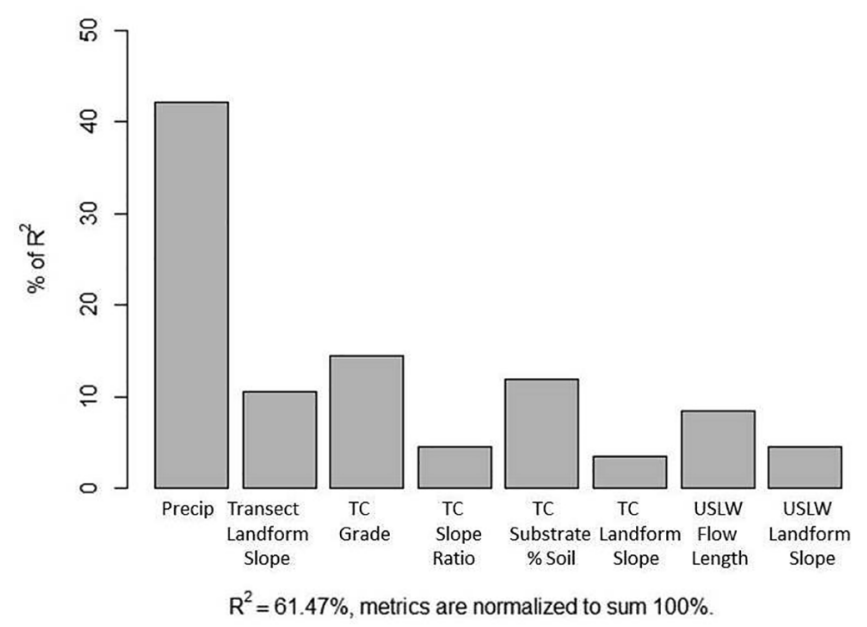

Fig. 5. The variable importance plot for the final combined spatial scale model (Adjusted $\mathrm{R}^{2}=0.57$ ). Metrics are standardized with a sum of $100 \%$. 
A.T. segments was used to validate the regression modeling results. Given the small sample size for the validation results, higher variance in model accuracy is expected. All four of the models performed with $\mathrm{R}^{2}$ above 0.43. Comparisons of model estimates for mean tread depth to field measured values found that the transect scale model performed the best, with an $R^{2}$ of 0.61 . While the combined spatial scale model had explained the highest percent of soil loss variance, the validation yielded a predicted vs. observed value correlation of $43 \%$.

\section{Discussion}

\subsection{Improvement of regression equations}

This study was designed to include substantial exploratory work in developing, collecting, and analyzing many new, to recreation ecology, field-measured and GIS-calculated variables. These included GIS surrogates for field-measured variables and new variables employing different analytical methods and spatial scales enabled by GIS software and LiDAR data (Table 2). The best CSA soil loss model presented in Olive and Marion (2009) included soil texture variables, use level and type, TSA, trail grade, and topographic position (adjusted $\mathrm{R}^{2}=0.32$ ). Trails with fall-line alignments and steeper slopes were most significantly correlated to soil loss. While this study used a different dependent variable to avoid the confounding influence of trail width, the prediction of soil loss achieved higher adjusted $R^{2}$ values. This was possibly due to the application of GIS and LiDAR terrain data employed in this study, which broadened the spatial extent of analysis and provided many new variables relating to soil erosion at different spatial scales.

The extensive regression modeling performed in this research yielded some interesting new variables that influence trail soil loss. Despite the very large number of potential explanatory variables and alternative measures, three of the models contained four or fewer predictors, an unexpected finding. However, the combined spatial scale model contained eight predictors, seven significant at the 0.05 threshold, and explained $57 \%$ of the variation in mean trail depth. Precipitation was the most influential variable, included in all four models $(\mathrm{p}<.001)$. While the amount of precipitation is expected to be an influential variable for trail soil loss, we also suspect that this variable, which was different for each A.T. segment but the same for each transect within segments, could possibly be accounting for variation due to differences in other factors which were not measured and evaluated. For example, amount of use and history of tread maintenance likely vary between segments but could not be accurately measured or assessed for inclusion in regression modeling. This is a potential study limitation that requires additional investigation.

As revealed in the regression modeling (Table 2) and the variable importance plot (Fig. 5), slope has different effects on soil loss at different spatial scales and was a significant factor when measured at each spatial scale in the combined model. Steeper slopes have more potential energy and water travels down them at faster rates, scouring and transporting soil along the way. Steeper trail grades correlate to higher levels of soil loss. However, greater slopes at the small scale-topography level, where landform slope was measured at the transects, also equate to higher soil loss. However, the landform slope of the trail corridor and the upslope watershed both have a negative relationship with soil loss at the transect. Within larger spatial watershed scales there can be substantial terrain variability and rugosity that shift or pool water flows and promote infiltration.

Upslope watershed flow length was included in the combined spatial scale model. Depending on landform slope and infiltration rates, longer flow lengths can allow more water to accumulate and run downhill, delivering more water to a trail.

The substrate of the trail corridor was recorded as either soil, rock at four size classes including bedrock, roots or human-placed wood. Soil was the only substrate type that was included as a significant variable in the regression models, with greater percent soil correlating to areas that are not very erosive and with lower soil loss. In steeper, generally rocky terrain, soils were shallow originally due to removal by glaciation.

\subsection{GIS surrogate data}

The resolution of DEM's has important implications on the accuracy of GIS data compared to field measurements. With $1 \mathrm{~m}$ data, slopes over an area larger than $3 \mathrm{~m}$ are relatively accurate, but with smaller areas DEM resolution becomes limiting. While some trail corridors were less than a few meters in length, most were longer. Regression modeling revealed that the slopes measured in the field at the transect and trail corridor scales were more strongly correlated than GIS-derived slope values, while landform and watershed slopes had higher correlations when using the GIS-derived layer. This is largely a function of scale. At the transect scale, $1 \mathrm{~m}$ resolution data appears to be insufficiently accurate to mirror field measurements. Dense vegetation and large rocks in some areas likely also hinder the accuracy of LiDAR-derived DEMs. GIS products were of greater utility at larger spatial scales and when not directly derived from the trail centerline. GIS measurement error occurs from relating point and line features to the grid design of the raster layer. Trail grades, alignments, and tread conditions and grades can change rapidly over short distances. GPS error in the accuracy of the trail centerline versus transect point data adds to uncertainty in GIS layers. These findings point to the need for more accurate LiDAR data, either from airborne or ground-based sensors, and to improved GPS accuracy in the collection of trail centerlines and transect points.

\subsection{Effect of spatial scale}

Spatial scale, both the grain and the extent can strongly influence the factors that are being modeled (Turner et al., 1989). To explore the resolutions that would best suit the ecological problem being modeled, we explored several different resolutions for topography variables $(1 \mathrm{~m}$, $10 \mathrm{~m}, \& 30 \mathrm{~m})$. When considering the variables that might influence trail soil erosion the spatial extent in which to frame the problem was considered. Previous field studies have limited their focus to the trail transect scale (Marion \& Wimpey, 2017; Olive \& Marion, 2009). Slope and TSA were measured at the trail transect, omitting watershed measures. This study sought to explore the effects of spatial scale by also framing trail erosion within the larger trail corridor and landform watershed perspectives. Variables that were significant to trail erosion entered and departed the model at differing spatial scales. For example, trail grade and TWI were included in the transect scale model but were omitted from the combined spatial scale model. This indicates that variables that were influential at a fine-scale are often less influential at larger scales, findings that are consistent with other soil erosion studies (Cammeraat, 2002; Cantón et al., 2011).

\subsection{Limitations}

The higher spatial resolution DEM used in this research improved $\mathrm{R}^{2}$ values for explaining soil loss compared to other studies (Cakir, 2005; Tomczyk, 2011), but the resolution may yet be insufficient, resolutions $<0.5 \mathrm{~m}$ are likely to improve correlations and insights. Trails can turn rapidly and undulate up and down slopes over short distances. The spatial information calculated at $1 \mathrm{~m}$ resolution may be too coarse for rapidly changing alignments or to account for small drainage features or out-sloped treads. Tread drainage features are very important for moving water off the trail but $1 \mathrm{~m}$ data does not accurately reflect these features.

Because the soil loss measure was used to train the model, the assumption is that trail characteristics associated with transects that have very high soil loss will predict other spots that could erode greatly. However, soil loss may be recorded as slight even when trail characteristics such as slope and fall-line alignment predict substantial soil 
loss due to shallow depth to bedrock. In the study area's mountainous terrain, the soils are frequently very thin, often because of past glaciation, and $2-5 \mathrm{~cm}$ of soil over bedrock are common. In these situations, if the trail was steep and aligned with the fall-line, trail erosion measures would be expected to be substantial, yet measured soil loss was sometimes small because the majority of soil had been removed during glaciation events. This common situation substantially reduced variation in the dependent variable and confounded the model's ability to accurately predict locations where highly eroded treads should occur, reducing correlations between predicted versus actual soil loss. Future studies should include a measurement of soil depth to bedrock near transects. Modeling in areas with less rock in tread substrates and with a substantial range in soil depth is even more desirable. In this study, modeling was limiting in its ability to accurately predict aggregate erosion, though it can more accurately predict areas that will erode quickly. Whether those areas will become eroded treads is a separate issue dependent on soil depth, since once bedrock is exposed the tread becomes stable.

\subsection{Trail management implications}

It is possible for trails to be sustainably designed and constructed and used for decades with very little environmental impacts to vegetation, soil, and water (Marion \& Wimpey, 2017; Marion, 2016). Trail design elements such as grade, alignment of the trail with the prevailing landform, rockiness of tread substrates, and soil type influence how a trail will resist degradation over time. This research indicates side-hill trail alignments are most sustainable and that less soil loss occurs with diminishing trail grades and increasing landform grades. Trail maintenance features such as grade reversals, out-sloped treads, drainage dips, and water bars divert water off trails. The density, efficacy, and maintenance of these features should be greater when precipitation increases, or when trail watersheds increase in size and landform steepness, as indicated by increasing trail watershed flow lengths and landform slopes.

Those involved in trail planning, design, construction, and maintenance manage how frequently these features are introduced to the trail depending on the topography and substrates the trail traverses. Consideration of where water is entering the trail corridor and of small scale- and macro-watershed attributes influence how sustainable the trail will be over time. Adapting design standards to differing geologic/ soil, vegetation, topographic, and watershed attributes should be considered in the design of sustainable trails or during relocations to avoid non-sustainable segments. Fixed, universally-applied trail design specifications may be both desirable yet unachievable. The combined spatial scale model presented in this paper offers some new insights for trail managers for environmental and trail design factors to consider when constructing and managing sustainable trails. Trail professionals are beginning to initiate trail design work using GIS capabilities, which increasingly allow the direct application of knowledge developed by studies like this one.

Finally, we note that in rocky terrain with thin soils over bedrock the traditional sustainable trail design guidance is less applicable since extensive soil loss cannot generally occur, though steep rocky trails can be unsafe or promote trail widening behaviors. Trail design that promotes visitors remaining on the designed tread remains an important objective to deter off-trail traffic that would damage trailside vegetation and soils. This suggests avoidance of tall "Paul Bunyan" steps or uneven treads with excessive rockiness or exposed roots. Soil depths ought to be considered when making decisions about the need for relocations and their design. A trail already eroded to bedrock is sustainable as long as it is safe and retains/concentrates visitor traffic, while an eroding trail in deeper soils is a better candidate for closure and rerouting.

\section{Conclusion}

The regression modeling developed in this study provided more accurate and significant predictions of soil loss on unsurfaced trails in comparison to earlier studies. In exploring three spatial scales and a final combined model using variables from all three spatial scales, we have identified several new soil loss relationships. GIS analyses with LiDAR data enabled the creation and use of many new trail corridor and upslope watershed variables that have not been considered in other trail studies but which are significantly correlated to soil loss.

Future studies can continue to develop and refine these types of trail soil loss models to develop an improved understanding of the variables that influence trail sustainability. Work in areas with deeper soils and less rockiness should improve the accuracy of predictive models. Continued work with improved GIS capabilities and finer resolution LiDAR data at different spatial scales are also likely to prove beneficial. In particular, the collection of ground-based LiDAR along trail-corridors appears to offer great promise in both evaluating trail impacts and sustainability and in monitoring trail degradation over time.

\section{CRediT authorship contribution statement}

Holly Eagleston: Conceptualization, Data curation, Formal analysis, Investigation, Methodology, Project administration, Resources, Software, Supervision, Validation, Visualization, Writing - original draft. Jeffrey L. Marion: Conceptualization, Formal analysis, Funding acquisition, Investigation, Methodology, Project administration, Resources, Software, Supervision, Validation, Visualization, Writing original draft, Writing - review \& editing.

\section{Acknowledgements}

We thank Chris Carr and Jeremy Wimpey for collaboration and assistance in sampling, protocol development, and fieldwork, and Brian Peterson, Dylan Spencer, Kaitlin Burroughs, Mary-Ellen Burnette, and Mitch Rosen for their dedicated assistance collecting field data. This study was funded by the US National Park Service, with guidance, collaboration, and contracting support provided by the Appalachian Trail Conservancy. Use of trade, product, or firm names is for descriptive purposes only and does not imply endorsement by the US Government.

\section{References}

Appalachian Trail Conservancy, About the Appalachian Trail. (2020). https:// appalachiantrail.org/home/about-us/media-room Accessed 13 Jan 2020.

Bodoque, J. M., Ballesteros-Canovas, J. A., Rubiales, J., Perucha, M. A., Nadal-Romero, E., \& Stoffel, M. (2017). Quantifying soil erosion from hiking trail in a protected aatural area in the Spanish Pyrenees. Land Degradation and Development, 28(7), 2255-2267. https://doi.org/10.1002/ldr.2755.

Cakir, J. (2005). Modeling Trail Degradation Using Field and GIS Methodologies: A Comparative Study. PhD Dissertation, Durham, NC: North Carolina State University. 178pp.

Cammeraat, L. (2002). A review of two strongly contrasting geomorphological systems within the context of scale. Earth Surface Processes and Landforms, 27, 1201-1222.

Cantón, Y., Solé-Benet, A., De Vente, J., Boix-Fayos, C., Calvo-Cases, A., Asensio, C., \& Puigdefábregas, J. (2011). A review of runoff generation and soil erosion across scales in semiarid south-eastern Spain. Journal of Arid Environments, 75(12), 1254-1261.

Cole, D. (1983). Assessing and monitoring backcountry trail conditions. Res. Pap. INT303. Ogden, UT: USDA For. Serv., Intermountain Forest and Range Exper. Stn.

Cwiakala, P., Kocierz, R., Puniach, E., Nedzka, M., Mamczarz, K., Niewiem, W., \& Wiacek, P. (2017). Assessment of the possibility of using unmanned aerial vehicles (UAVs) for the documentation of hiking trails in alpine areas. Sensors, 18, 81. https://doi.org/10, 3390/s18010081.

DeBoer, D. (1992). Hierarchies and spatial scale in process geomorphology: A review. Geomorphology, 4, 303-318.

Greve, M., Kheir, R., Greve, M., \& Bocher, P. (2012). Quantifying the ability of environmental parameters to predict soil texture fractions using regression-tree model with GIS and LiDAR data, The case study of Denmark. Ecological Indicators, 18, 1-10.

Hawes, M., Dixon, G., \& Ling, R. (2013). A GIS-based methodology for predicting walking track stability. Journal of Environmental Management, 115, 295-299. 
Horn, B. P. (1981). Hillshading and the reflectance map. Proceedings of the IEEE, 69(1), $14-47$.

Jebur, M., Pradhan, B., \& Tehrany, M. (2014). Optimization of landslide conditioning factors using very high-resolution airborne laser scanning (LiDAR) data at catchment scale. Remote Sensing of the Environment, 152, 150-165.

Jebur, M., Pradhan, B., \& Tehrany, M. (2015). Manifestation of LiDAR-derived parameters in the spatial prediction of landslides using novel ensemble evidential belief functions and support vector machine models in GIS. IEEE Selected Topics in Applied Earth Observations and Remote Sensing, 8(2), 674-690.

Lane, L., Hernandez, M., \& Nichols, M. (1997). Processes controlling sediment yield from watershed as function of spatial scale. Environmental Modelling \& Software, 12(4), 355-369.

Leung, Y.-F., \& Marion, J. L. (1996). Trail degradation as influenced by environmental factors, a state-of-knowledge review. Journal of Soil \& Water Conservation, 51, $130-136$.

Leung, Y.-F., \& Marion, J. L. (1999). The influence of sampling interval on the accuracy of trail impact assessment. Landscape and Urban Planning, 43(4), 167-179.

Leung, Y.-F., Marion, J. L., \& Farrell, T. (2001). The role of recreation ecology in sustainable tourism and ecotourism. In S. F. McCool, \& N. Moisey (Eds.). Tourism Recreation and Sustainability, Linking Culture and Environment (pp. 21-39). Oxon: CABI Publishing.

Marion, J. L. (2016). A Review and synthesis of recreation ecology research supporting carrying capacity and visitor use management decision-making. Journal of Forestry, 114(3), 339-351.

Marion, J. L., Hockett, K. (2008). Frontcountry recreation site and trail conditions: Haleakalä National Park. Final Research Rpt., Blacksburg, VA: USDI, U.S. Geological Survey, Virginia Tech Field Station. 88p.

Marion, J. L., Leung, Y. -F., Nepal, S. (2006). Monitoring trail conditions, new methodological considerations. The George Wright Forum, 23(2), 36-49.

Marion, J. L., Wimpey, J., Park, L. (2011). The science of trail surveys: Recreation ecology provides new tools for managing wilderness trails. Park Science, 28(3), 60-65.

Marion, J. L., Leung, Y.-F., Eagleston, H., \& Burroughs, K. (2016). A review and synthesis of recreation ecology research findings on visitor impacts to wilderness and protected natural areas. Journal of Forestry, 114(2), 352-362.

Marion, J. L., \& Wimpey, J. (2017). Assessing the influence of sustainable trail design and maintenance on soil loss. Journal of Environmental Management, 189, 46-57.

Meadema, F., Marion, J. L., Arredondo, J., \& Wimpey, J. (2020). The influence of layout on Appalachian Trail soil loss, widening, and muddiness: Implications for sustainable trail design and management. Journal of Environmental Management, 257. https://doi. org/10.1016/j.jenvman.2019.109986.

National Park Service. (2006). Management Policies. Washington DC: USDI National Park Service.

Olive, N., \& Marion, J. L. (2009). The influence of use-related, environmental and managerial factors on soil loss from recreational trails. Journal of Environmental Management, 90(3), 1483-1493.

Perroy, R., Bookhagen, B., Asner, G., \& Chadwick, O. (2010). Comparison of gully erosion estimates using airborne and ground-based LiDAR on Santa Cruz Island, California. Geomorphology, 118(3), 288-300.

Peterson, B. A., Brownlee, M. T., \& Marion, J. L. (2018). Mapping the relationships between trail conditions and experiential elements of long-distance hiking. Landscape and Urban Planning, 180, 60-75.
Poesen, J., Torri, D., \& Bunte, K. (1994). Effects of rock fragments on soil erosion by water at different spatial scales, a review. Catena, 23, 141-166.

PRISM Climate Group. (2004). 30-yr Annual Normal Precipitation, 1981-2010. Oregon State University, http://prism.oregonstate.edu, created 4 Feb 2004.

Rangel, L. A., Jorge, M. C. O., Guerra, A. J. T., \& Fullen, M. (2019). Soil erosion and land degradation on trail systems in mountainous areas: Two case studies from South-East Brazil. Soil Systems, 3(3), 56. https://doi.org/10.3390/soilsystems3030056.

Rodway-Dyer, S., \& Ellis, N. (2018). Combining remote sensing and on-site monitoring methods to investigate footpath erosion within a popular recreational heathland environment. Journal of Environmental Management, 215, 68-78. https://doi.org/10. 1016/j.jenvman.2018.03.030.

Rodway-Dyer, S., \& Walling, D. E. (2010). The use of ${ }^{137} \mathrm{Cs}$ to establish longer-term soil erosion rates on footpaths in the UK. Journal of Environmental Management, 91, 1952-1962. https://doi.org/10.1016/j.jenvman.2010.04.014.

Römkens, M., Helming, K., \& Prasad, S. N. (2002). Soil erosion under different rainfall intensities, surface roughness, and soil water regimes. Catena, 46(2), 103-123.

Salesa, D., \& Cerda, A. (2019). Four-year soil erosion rates in a running-mountain trail in Eastern Iberian Peninsula. Geographical Research Letters, 45(1), 301-331. https://doi. org/10.18172/cig.3826.

Sankey, J., Glenn, N., Germino, M., Gironella, A., \& Thackray, G. (2010). Relationships of aeolian erosion and deposition with LiDAR-derived landscape surface roughness following wildfire. Geomorphology, 119(1), 135-145.

Smith, M. (2014). Roughness in the earth sciences. Earth-Science Reviews, 136, 202-225.

Stambaugh, M., \& Guyette, R. (2008). Predicting spatio-temporal variability in fire return intervals using a topographic roughness index. Forest Ecology and Management, 254(3), 463-473.

Stevens, D., \& Olsen, A. (2004). Spatially-balanced sampling of natural resources. Journal of American Statistical Association, 99(465), 262-278.

Tarolli, P., Calligaro, S., Cazorzi, F., \& Fontana, G. (2013). Recognition of surface flow processes influenced by roads and trails in mountain areas using high-resolution topography. European Journal of Remote Sensing, 46, 176-197.

Tomczyk, A. (2011). A GIS assessment and modelling of environmental sensitivity of recreational trails, The case of Gorce National Park, Poland. Applied Geography, 31, 339-351.

Tomczyk, A., \& Ewertowski, M. (2013). Planning of recreational trails in protected areas, Application of regression tree analysis and geographic information systems. Applied Geography, 40, 129-139.

Tomczyk, A., Ewertowski, M. W., White, P. C., \& Kasprzak, L. (2017). A new framework for prioritising decisions on recreational trail management. Landscape \& Urban Planning, 167, 1-13.

Travis, M., Elsner, G., Iverson, W., Johnson, C. (1975). VIEWIT, computation of seen areas, slope, and aspect for land-use planning. Gen. Tech. Rep. PSW-11, Berkeley, CA: USDA Forest Service, Pacific Southwest Forest and Range Exp. Stn. 70pp.

Turner, M., O'Neil, R., Gardner, R., \& Milne, B. (1989). Effects of changing spatial scale on the analysis of landscape pattern. Landscape Ecology, 3, 153-164.

Vinson, J. A., Barrett, S. M., Aust, W. M., \& Bolding, M. C. (2017). Evaluation of bladed skid trail closure methods in the Ridge and Valley Region. Forest Science, 63(4), 432-440. https://doi.org/10.5849/FS.2016-030R1.

Wimpey, J., \& Marion, J. L. (2010). The influence of use, environmental and managerial factors on the width of recreational trails. Journal of Environmental Management, 91(10), 2028-2037. 